\title{
ASSISTÊNCIA SOCIAL COMO LINHA DE FRENTE DAS POLÍTICAS PÚBLICAS ANTE A PANDEMIA DO COVID-19
}

\section{ARTIGO ORIGINAL}

ABEGG, Caroline ${ }^{1}$

ABEGG, Caroline. Assistência Social como Linha de Frente das Políticas Públicas Ante a Pandemia do Covid-19. Revista Científica Multidisciplinar Núcleo do Conhecimento. Ano 05, Ed. 08, Vol. 05, pp. 25-32. Agosto de 2020. ISSN: 24480959, Link de acesso: https://www.nucleodoconhecimento.com.br/cienciassociais/linha-de-frente

\section{RESUMO}

Esse texto discute, através de teses, artigos e buscas cientificas realizadas sobre esse assunto, o papel da assistência social na linha de frente das políticas públicas de assistência social ante os efeitos sociais causados pela pandemia pela perspectiva da garantia de direitos a população em vulnerabilidade social. Além de retratar como objetivo o que é preciso ser feito, falado e pensado em relação a essa doença e a essa pandemia.

Palavras-Chave: Garantia de Direitos, pandemia, Políticas Públicas, vulnerabilidade social.

${ }^{1}$ Pós Graduada Gestão de Pessoas pela Universidade Luterana do Rio Grande do Sul (ULBRA). Pós Graduada Gestão em Serviço Social e Projetos Sociais pela Faculdade Venda Nova do Imigrante (FAVENI). Graduada em Serviço Social Universidade Regional do Noroeste do Estado do Rio Grande do Sul (UNIJUÍ). 


\section{INTRODUÇÃO}

Desde o início de 2020 já vinhamos acompanhando os efeitos do novo Coronavírus (SARS-CoV-2), ou COVID-19 no mundo, conforme a Organização Pan-Americana de Saúde (OPAS BRASIL):

De acordo com a Organização Mundial da Saúde (2020) houve a declaração de que no dia 30 de janeiro de 2020 o surto da doença causada pelo novo coronavírus constituiu uma Emergência de Saúde Pública de Importância Internacional. Conforme previsto no Regulamento Sanitário Internacional esse foi o maior nível de alerta da Organização. A COVID-19 foi caracterizada como uma pandemia, pela OMS, em 11 de março de 2020.

Mudando assim significativamente nosso modo de agir e interagir em sociedade, criando novos hábitos de higiene e convivência, enfraquecendo vínculos muitas vezes já fragilizados, seus efeitos são ainda mais implacáveis com a população em vulnerabilidade social, a qual é público alvo de atendimento das políticas públicas de assistência social.

Se torna mais visível e mais aguda a crise, a situação de calamidade pública que estamos envolvidos(as) quando se tornou exposta a forma frouxa das contrarreformas neoliberais em nosso país, favorizando os interesses de grande capital e em detrimento das precisões urgentes e dos direitos das classes trabalhadoras. (YAZBEK; RAICHELIS; SANT'ANA, 2020, p.207)

A pandemia tem escancarado as situações de vulnerabilidade e evidencia cada vez mais as desigualdades sociais, restringido e negando direitos nas mais diferentes áreas.

\section{DESENVOLVIMENTO}

A assistência Social tem atuado na linha de frente das Políticas Sociais voltadas para as novas expressões da questão social que vem surgindo em virtude da atual pandemia. 
As condições vivenciadas pelo país em níveis políticos, sociais e econômicos estão diretamente ligadas com as políticas sociais do Brasil. Sendo vistas como meios de manutenção da força de trabalho, como conquistas dos trabalhadores, ou como meio de garantia do aumento de riquezas ou dos direitos do cidadão, ou até mesmo como doação das elites dominantes. (FALEIROS, 1991)

Em seu Art. 2ํ- - III a Lei Orgânica de Assistência Social (LOAS) tem como um de seus objetivos "a defesa de direitos, que visa a garantir o pleno acesso aos direitos no conjunto das provisões socioassistenciais". Mas como garantir direitos em meio ao atual contexto das famílias que vivem situação de vulnerabilidade social que já vinham de certa forma vivenciando em um isolamento social, em virtude a falta de acesso ao trabalho, saneamento básico, saúde, educação e alimentação de qualidade.

De acordo com o Manifesto do CFESS (2020), os dados da OMS (Organização Mundial da Saúde) e da ONU (Organização das Nações Unidas) ocorreu a indicação de que as populações mais pobres serão as mais atingidas pelo COVID-19. Pois no Brasil, a grande parte da população não tem acesso às políticas sociais que possuem uma boa qualidade.

Junto com toda a crise sanitária que vem se agravando a crise financeira vem sofrendo fortes impactos que têm afetado de formal significativa os trabalhadores informais e os profissionais liberais, os quais muitos desses têm se tornado público de atendimento das políticas sociais, aumentando assim a grande procura pela assistência social, gerando uma nova demanda para essa política.

A assistência social faz parte do tripé da seguridade social, juntamente com saúde e educação, políticas públicas essas que vem padecendo fortes impactos. Conforme Art. 203 da Constituição Federal (1988), considerada a Constituição Cidadã, "A assistência social será prestada a quem dela necessitar, independente de contribuição a seguridade social".

Surge a necessidade de adequação da política pública para dar conta dessa nova demanda que vem surgindo juntamente com a pandemia, onde verifica-se com muita 
frequência a inexistência de ofertas de serviço que possibilitem a subsistência das famílias. Conforme Instituto Brasileiro de Geografia e Estatística (IBGE) no primeiro trimestre de 2020 fui de 11,9\%, 12, 9 milhões de desempregados, números esses que têm perspectiva de aumento em consequência da crise sanitária e do avanço da política neoliberal.

Para dar conta das seguranças afiançadas pela política de assistência é necessário medidas imediatas que requerem recursos vultuosos por parte do poder público.

Art. 4ํㅗ̃o seguranças afiançadas pelo SUAS:

I - Acolhida: provida por meio da oferta pública de espaços e serviços para a realização da proteção social básica e especial, devendo as instalações físicas e a ação profissional conter:

a) Condições de recepção;

b) Escuta profissional qualificada;

c) Informação;

d) Referência;

e) Concessão de benefícios;

f) Aquisições materiais e sociais;

g) Abordagem em territórios de incidência de situações de risco;

h) Oferta de uma rede de serviços e de locais de permanência de indivíduos e famílias sob curta, média e longa permanência.

II - Renda: operada por meio da concessão de auxílios financeiros e da concessão de benefícios continuados, nos termos da lei, para cidadãos não incluídos no sistema contributivo de proteção social, que apresentem vulnerabilidades decorrentes do ciclo de vida e/ou incapacidade para a vida independente e para o trabalho;

III - Convívio ou vivência familiar, comunitária e social: exige a oferta pública de rede continuada de serviços que garantam oportunidades e ação profissional para: 
a) A construção, restauração e o fortalecimento de laços de pertencimento, de natureza geracional, intergeracional, familiar, de vizinhança e interesses comuns e societários;

b) O exercício capacitador e qualificador de vínculos sociais e de projetos pessoais e sociais de vida em sociedade.

IV - Desenvolvimento de autonomia: exige ações profissionais e sociais para:

a) O desenvolvimento de capacidades e habilidades para o exercício do protagonismo, da cidadania;

b) A conquista de melhores graus de liberdade, respeito à dignidade humana, protagonismo e certeza de proteção social para o cidadão e a cidadã, a família e a sociedade;

c) Conquista de maior grau de independência pessoal e qualidade, nos laços sociais, para os cidadãos e as cidadãs sob contingências e vicissitudes.

V - Apoio e auxílio: quando sob riscos circunstanciais, exige a oferta de auxílios em bens materiais e em pecúnia, em caráter transitório, denominados de benefícios eventuais para as famílias, seus membros e indivíduos.

Não garantir as seguranças afiançadas pela política de assistência social é negar os direitos básico, é violar nossa Carta Magna e é não garantir os direitos humanos. De acordo com a Declaração Universal dos Direitos Humanos (1948):

Art. 22 Todo ser humano, como membro da sociedade, tem direito à segurança social, à realização pelo esforço nacional, pela cooperação internacional e de acordo com a organização e recursos de cada Estado, dos direitos econômicos, sociais e culturais indispensáveis à sua dignidade e ao livre desenvolvimento da sua personalidade.

Estamos vivenciando um momento atípico, de uma crise de dimensão mundial, com consequências ainda imensuráveis a longo prazo, principalmente os impactos na população em vulnerabilidade social. Segundo Bruseke (2006, p.69-80) "Compreende-se, portanto, a vulnerabilidade como uma conjunção de fatores, sobrepostos de diversas maneiras e em várias dimensões, de modo a tornar o indivíduo ou grupo mais suscetível aos riscos e contingências". As consequências para sobrevivência nesse momento pandêmico e pós-pandêmico se monstra ainda 
mais perverso nessa parcela da polução, fazendo surgir assim novas expressões e configurações da questão social, que conforme Lamamoto (2018, p.72):

Condensam múltiplas desigualdades mediadas por disparidades nas relações de gênero, características étnico-raciais, mobilidades espaciais, formações regionais e disputas ambientais, colocando em causa amplos segmentos da sociedade civil no acesso aos bens da civilização. Dispondo de uma dimensão estrutural - enraizada na produção social contraposta à apropriação privada do trabalho -, a questão social atinge visceralmente a vida dos sujeitos numa luta aberta e surda pela cidadania, no embate pelo respeito aos direitos civis, sociais e políticos e aos direitos humanos

A fim de tentar amenizar essa situação de urgência/emergência é necessário é necessário materializar direitos sem banalizá-los e não apenas reconhecê-los, com o objetivo de minimizar os efeitos sociais caudados pelo Covid-19. Yazbek; Raichelis; Sant'Ana (2020, p.212) “Em tempos de desmonte das frágeis e insuficientes políticas públicas, esse é um quadro que interpela profundamente aqueles(as) que buscam uma outra sociabilidade para além do capital."

Os profissionais inseridos nessa linha de frente de atuação das políticas públicas de assistência social precisam ter um cuidado redobrado não aceitar e nem contribuir para a violência institucional em virtude da alta demanda e dos protocolos de segurança sanitária, entrando na dicotomia do que pode e do que deve ser feito, pois entende-se que o distanciamento físico se faz necessário, porém grande parte do trabalho realizado na linha de frente políticas públicas voltadas para as expressões da questão social se fazem de maneira presencial, como visitas domiciliares e atendimentos individualizados, sendo necessário um cuidado redobrado para garantir a segurança do usuário e do próprio profissional. CFESS (2020) ao manifestar-se sobre o trabalho remoto concluiu que algumas atividades do cotidiano profissional não são compatíveis com tal modalidade de trabalho.

Entre os protocolos previstos para os órgãos gestores da política de assistência social como medidas de prevenção, cautela e redução do risco de transmissão o Art. 3 o da Portaria no 337, de 24 de março de 2020 traz: 
I - Adoção de regime de jornada em turnos de revezamento em que se promova melhor distribuição da força de trabalho com o objetivo de evitar a concentração e a proximidade de pessoas no ambiente de trabalho;

II - Adoção de medidas de segurança para os profissionais do SUAS com a disponibilização de materiais de higiene e Equipamentos de Proteção Individual - EPI, recomendados pelo Ministério da Saúde, afastamento ou colocação em teletrabalho dos grupos de risco;

III - Observar no âmbito dos equipamentos e serviços socioassistenciais as orientações do Ministério da Saúde com relação ao cuidado e prevenção da transmissão nos termos da Cartilha do Ministério da Saúde "Tem dúvidas sobreo Corona Vírus" disponível no link https://coronavirus.saúde.gov.br/ ou no http://blog.mds.gov.br/redesuas/wpcontent/uploads/2020/03/Informacoe s_Coronavirus_Minist\%C3\%A9rio_da_Saude.pdf, em especial nos Serviços de Acolhimentos, no Serviço de Proteção Social Especial para pessoas com Deficiência, idosas e suas Famílias e no Serviço Especializado para Pessoas em Situação de Rua.

IV - Flexibilizar as atividades presenciais dos usuários no âmbito dos Centros de Referência da Assistência Social - CRAS e dos Centros Especializados de Assistência Social - CREAS, com vistas a reduzir a circulação de pessoas e evitar a aglomeração nos equipamentos;

V - Intensificar as atividades de:

a) disseminação de informação aos usuários acerca do cuidado e prevenção da transmissão, conforme orientações do Ministério da Saúde;

b) Disseminação de informações à rede socioassistencial aos profissionais usuários do SUAS acerca das estratégias e procedimentos que serão adotados para assegurar as ofertas essenciais; e

c) Acompanhamento remoto dos usuários, por meio de ligação telefônica ou aplicativos de mensagens - como WhatsApp, principalmente daqueles tidos como grupos de risco, tais como idosos, gestantes e lactantes, visando assegurar a sua proteção.

$\mathrm{VI}$ - Organizar a oferta dos serviços, programas e benefícios

socioassistenciais preferencialmente por agendamento remoto, priorizando os atendimentos individualizados graves ou urgentes, evitando-se a aglomeração de pessoas nas salas de espera ou recepção das unidades; 
VII - Realização de atendimentos individuais em ambientes amplos, arejados e constantemente limpos, atentando para a garantia de sigilo e privacidade do atendimento, ainda que se opte por realizá-los em locais abertos como varandas, quintais, tendas, etc; $\mathrm{e}$

VIII - Suspensão temporária de eventos, encontros, cursos de formação, oficinas, entre outras atividades coletivas.

Entretanto esses protocolos precisam ser tomados com muito cuidado, para não enfraquecer os vínculos já criados com os usuários do Sistema Único de Assistência social (SUAS), por se tratarem em grande parte de população com vínculos famílias e comunitários já fragilizados ou rompidos.

\section{CONSIDERAÇÕES FINAIS}

Precisa-se mais que nunca ter empatia, uma escuta e um olhar sensível para conseguir se analisar a nova realidade social vivenciada. Criar estratégias para se conseguir garantir direitos já consolidados legalmente. Com o propósito de garantir a proteção social nesse momento tão incerto.

Mesmo com o aumento das políticas públicas voltada para a atual realidade, ainda se faz muito pouco, pois as demandas aumentam de suas formas mais variadas no cotidiano, tornando-se assim um grande desafio por parte do poder público e dos profissionais inseridos nessas políticas a darem conta com um resultado eficiente $\mathrm{e}$ de qualidade que resulte em na garantia de direitos, dignidade e cidadania a população.

Os profissionais que estão atuando nessa linha deve ter um posicionamento éticopolítico e cuidar para não acabar tendo uma postura messiânica utópica ou fatalítica.

\section{REFERÊNCIAS}

BRASIL. Constituição (1988). Constituição da República Federativa do Brasil: promulgada em 5 de outubro de 1988. 
BRASIL. Presidência da República. Lei Orgânica da Assistência Social. Lei № 8.742, de 7 de Dezembro de 1993.

BRASIL. Ministério da Cidadania. Dispõe acerca de medidas para o enfrentamento da emergência de saúde pública de importância internacional decorrente do coronavírus, COVID-19, no âmbito do Sistema Único de Assistência Social. Portaria no 337 , de 24 de março de 2020

CFESS. Os impactos do Coronavírus no trabalho do/a assistente social. Brasília, Manifesto de 23 de março de 2020. Disponível em http://www.cfess.org.br/arquivos/2020CfessManifestaEdEspecialCoronavirus.pdf. Acessado em 07 de agosto de 2020.

FALEIROS, Vicente de Paula. O que é política social. 5. ed. São Paulo: Brasiliense, 1991.

IAMAMOTO, Marilda Villela. Serviço Social, "questão social" e trabalho em tempo de capital fetiche. In: RAICHELIS, R. et al. (orgs.) A nova morfologia do trabalho no Serviço Social. São Paulo: Cortez, 2018.

Instituto Brasileiro de Geografia e Estatística (IBGE). Disponível em: https://www.ibge.gov.br/explica/desemprego.php . Acessado em: 08 de agosto de 2020.

RUSEKE, Franz Josef. Risco e Contingência. O s paradigmas da modernidade e sua contestação. Revista Brasileira de Ciências Sociais, 1 ed. Florianópolis: Editora Insular, 2006, 69-80 pp

YAZBEK, Maria Carmelita; RAICHELIS, Raquel; SANT'ANA, Raquel. Questão social, trabalho e crise em tempos de pandemia. Serviço Social e Sociedade. São Paulo. no 138. p 207-213, maio/agosto 2020.

Enviado: Agosto, 2020.

Aprovado: Agosto, 2020. 